\title{
Collaboratively Building Digital Libraries: Focus on Local Historical Resources for Educational Use
}

\author{
Zainab A.N., Abrizah Abdullah and W.K. Ng \\ MLIS Program \\ Faculty of Computer Science \& Information Technology \\ University of Malaya, \\ 50603 Kuala Lumpur \\ Malaysia \\ zainab@fsktm.um.edu.my; abrizah@fsktm.um.edu.my
}

\begin{abstract}
COREDEV (Collaborative Resource Development) is a proposed digital library for historical resources that supports the development of digital content collaboratively. A prototype biographical portal that could handle information on Malaysian personalities was chosen as the domain for the test-bed. The biographical portal incorporates five main basic features: (a) uploading, indexing, searching and retrieval modules supports the creation, capturing and sharing of historical data from distributed sites and user groups (This environment helps produce the desired outcome in terms of ICT literate teachers and students and provide the experience of creating or publishing in digital libraries); (b) supporting multi-format digital resources (text, images, audio and video clips); (c) providing a facility for searching the contents of the digital libraries from simple keyword searches, specific occurrences of words in specific fields and a combination of terms using Boolean operators; (d) providing user controlled display (user may choose search and retrieval screens either in Malay or English language, determine the number of results to be displayed $(5,10$ or 20 records and browse thumbnail objects before zooming on specific details); (e) ensuring basic security features (authentication, registration of users and requirements of validation for all uploads by members before it is searchable through the Internet). Other information provided includes a brief introduction about the system, frequently asked questions (FAQ), terms and conditions for those interested in participating, help and edutainment features and linkages to other related resources.
\end{abstract}

\section{Introduction}

A digital library is defined as a library that contains material in digitized form or contains digital material (Noerr, 2000). Borgman, et al (1996) describes digital libraries as a set of electronic resources and associated technical capabilities for creating, searching and retrieving information. Digital libraries are an extension of information storage and retrieval systems that manipulate digital data in varied medium (text, sound, static or dynamic images) and exist in distributed networks. The content of digital libraries include data, metadata that describes the data and metadata that links to other data and metadata, whether internal or external to the digital library. Digital libraries may incorporate both retrospective digitized materials and materials that exist only in digital form. IBM DB2 Digital Library (1998) 
proposes that any functional digital library should contain five main components. It should provide for creating and capturing materials (supporting an array of industry standard specification, able to define and import data in varied format, incorporate templates and authoring tools to help in the creation process). It should include an access and distribution module so that information can be distributed over public or private networks (this includes utilising network management software, which assists fast data delivery both text, image or real time audio and video). The digital library should provide the search and retrieval components so that the contents of stored objects can be searched effectively (keywords, Boolean searches and ranking relevant results). Another necessary component is the authentication and rights management module that control user access and protects library contents. Finally, digital libraries should incorporate the storage and digital objects management module that provides high-performance, scalable storage and efficient objects management. The proposed collaborative digital library of historical resources will incorporate the above components.

There are numerous examples of digital libraries of historical resources currently available on the World Wide Web (WWW) and this paper will highlight a few. A fine example is the American Memory of the Library of Congress (AMLC). This is a National Digital Library Programme initiated by the US government to digitize and deliver historical resources held at the Library of Congress. The resources include photographs, manuscripts, rare books, maps, recorded sound and moving pictures. This digital library contains over seven million digital items and covers more than 100 historical American collections. Another impressive initiative is the New York Public Library Digital Library Collection. This digital library provides digital versions of books, manuscripts, and engravings. The New Zealand Digital library project was the result of a research programme to develop the underlying technology for digital libraries and making it available publicly so that those interested could create their own collections. This digital library provides several types of materials, which includes historical documents, technical reports, bibliographies, literary works and magazines. It also includes non-roman script collections (Arabic and Chinese). Malaysia's national attempt at developing a digital library is exemplified by Mylibrary, which is a pilot project developed under the Malaysian National Digital Library initiative comprising partnerships between National Library of Malaysia, Multimedia Development Corporation, Telekom Malaysia, selected government and state public libraries. MyLib's digital collection is organized into seven categories, books, e-zines, newspapers, multimedia, conferences, maps and reports. This digital library does not in itself develop its own eresources but create hyperlinks to other digital resources available on the Web (both Malaysian and foreign). MyLib is similar to the cooperative project reported by Carpenter (2000), where sixteen member libraries in Northeastern Wisconsin collaborate to publish an annotated listing with links to web sites and portals. COREDEV is the proposed digital library for historical resources that can be collaboratively used by educational and public institutions to develop digital resources. A description of the proposed systems architecture will be given in the next section. To ascertain the possibility of the proposal, a proto-type system was developed and a biographical portal of selected Malaysian personalities is chosen as the domain for the test bed.

It is clear that the way scholars, students and the public search and use information are changing. Highly improved ICT networks enables the digitization of resources and these situations have significant impact on the way teaching and learning are taking place as well as the way resources that support these situations are presented and organized. The value of digital resources subsequently, depends on the search and retrieval functions provided; the 
quality and format of the content, the organization of information as well as the data management system.

Digital libraries contribute to current learning environment in a number of ways. It helps provide the means to collect, store and organize digital information. It is able to provide information whenever and wherever it is needed. It revolutionizes the traditional pedagogy of providing learning resources and the way resources can be accessed. It helps students to practice self-accessed and self-directed reference learning at their own pace. It changes the conventional process of seeking information. It changes the speed and spread of information obtained.

\section{Why Collaborative Digital Library?}

Individual institution looking for solutions to manage and preserve their non-book resources initiated most of the digital libraries mentioned previously. The move towards collaboratively building a union digital library is a fairly recent trend.

Bunker and Zick (1999) describe an example of a successful image management system collaboratively developed by the University of Washington Digital Libraries Initiative, which evolve as a result of collaboration between faculty members, engineers, students and librarians. The collaboration focuses on the creation, use, and investigation of electronic services, resources and systems. The outcome is an image archiving software called CONTENT. In this collaboration, users can learn to digitize and manage their visual resource collections as well as integrate them into their research and curriculum. The libraries uses SQL-based digital registry to which, meta data is mapped from innovative interfaces. The locally developed resources comprise unique holdings and primary resources of about 26,000 images from a theatrical photograph collection and this grew to include maps, guides, diaries, moving images, oral histories and diaries. Besides this, the library also provides access to commercial electronic indexing and abstracting databases, catalogues and web sites. This effort results in an increase in the use of unique resources, which would be otherwise be inaccessible and referenced. All this is possible due to collaboration between departments and divisions within the university such as the University libraries' Special collection, the University Archives and Manuscript Division, Henry Art Gallery, the University of Washington Press, Seattle's Museum of History and Industry and Eastern Washington State Historical Society. The Library of Congress and Ameritech is funding the University Libraries to digitize 2,500 images and 6,00 pages of text on the history and culture of the native people of the Pacific Northwest. The materials can be assessed through CONTENT and become part of LC's American Memory site. CONTENT is a client-server system with full text, provide concept based searching, storage and access to visual media. Objects found in the search are displayed as thumbnails, which can be viewed by clicking on each image. It has rich metadata support and uses an open web-based standard. It allows for distributed storage and cataloging, supporting multiple asynchronous database building so that archivists, librarians and scholars can collaborate to define rich and complex metadata. The software package consists of a server, which runs on NT or Linux, user clients in Visual Basic or Java, image acquisition and administrative tool.

Another collaboration in building digital libraries of historical resources is the Greater Cincinnati Memory Project, which was officially launched in June 2000 (Tull, 2002). It involved twelve members from all types of libraries in Greater Cincinnati including northern Kentucky. The focus of the project was building local history materials accessible through the 
WWW. It began with the digitization of 6,000 pre-1940 photographs, slides and postcards relating to landmarks and events of local interests. Member libraries contribute all resources. Most member libraries were interested in digitizing their special collection but had no expertise or funds to undertake the project on their own. A consortium was established comprising an art museum, historical society library, public libraries, and university libraries. The initial project moved on an initial budget of US\$81,486.00 and the project team was structured to include:

(a) Contents committee, which was responsible for selecting, handling and watermarking materials, deciding on the type of format to be given priority (postcards, slides, photographs), deciding on the type of contents which the format should have (buildings, structures, locations, landmarks, businesses, objects, and events), and deciding on the state of materials to be included (high quality).

(b) Metadata/cataloguing committee, which was responsible for training cataloguers responsible for creating metadata for the images and describing the images using templates. The Dublin core standard was used to create the metadata.

(c) Technology Committee, which was responsible for all hardware and software related issues. This committee is responsible for the purchase of a server to house the images, technical specifications to scan the materials, design the database.

Hedman (1999) pointed out that in the electronic world situation, anyone could be both an author and a publisher. This situation perpetuates the creation of communal resources in cooperation. The digital library houses the possibility of being both an information storage facility as well as tools for production. The existing entities allow for the dynamic generation of content. This enables the creation of digital libraries from grass root levels. Hedman views digital libraries as collectively constructed through networking infrastructures and can be used to construct communal repositories of knowledge resources. In the educational context, this type of collaborative venture brings about the achievement of a number learning objectives.

- Creation of content collaboratively - It allows students and teachers to cooperate in building their own multimedia digital libraries.

- Enhance IT literacy - It provides the possibility of learning through the very act of collaboration. Students sharpen their skills through publishing works in various format to be shared by others (Stahl, 2000) and using digital libraries on the Internet to learn about IT and Internet technologies at the same time. Students will learn about subjects they are studying through creating their own part of the digital library.

- Creative presentation of content - using multimedia elements (java applet, shockwave, dynamic HTML) allows for concepts to be visualized and portrayed in a variety of ways. The contents can also reside elsewhere but can be assessed through the WWW.

These objectives are similarly embedded into the proposal of COREDEV. Digital libraries of local historical resources that cater for the Malaysian learning community is lacking. As the test bed for COREDEV is in the domain of biographical portals, a brief search on the Internet indicates that short biographies are available and mainly provides information in plain HTML text. Some very good examples are The P.Ramlee Project (http://www. farahaqil.com/download/audio/index.htm); Story of Yap Ah Loy (http://yapahloy.tripod.com. com/index1.htm), Tun Hussein Oon (http://www.eumno.net.my/news/tokoh /tunhussein.html) and Leftenan Adnan (http://army.mod.gov.my/It_adnan/. Only the P.Ramlee site gives multimedia resources, comprising lyrics, movie as well as audio clips, 
biodata, photograph images, and cartoon caricatures. The proposed biographical portal could support multimedia resources and provide searching and browsing facilities.

\section{The Proposal}

The proposed digital library (COREDEV) aims to provide an electronic system to help educators as well as students obtain information on local history; collect, store and organize information in digital format; publish and share electronic resources; learn how to use IT to obtain historical information. The digital library project conceptualizes the following objectives:

(a) To develop a repository platform to preserve local history resources, and in this context, a test-bed for Malaysian biographical information;

(b) To instill interests among educators, students and the general community on publishing historical information electronically;

(c) To make local historical resources accessible through the Internet;

(d) To develop an effective and efficient search system that can retrieve information from multi-format resources (textual data, graphics, images, audio and video files);

(e) To develop template-based systems that makes indexing multimedia contents easy for resource managers;

(f) To develop a relevancy ranking algorithm that could be utilized in query searches;

(g) To create a user friendly and consistent interface;

(h) To ensure authorized access to the management functions of the system; and

(i) To encourage and strengthen collaboration and sharing of historical resources between partner members.

\section{The Pilot Fact Finding}

In order to ascertain the basic features needed for the system, a pilot survey was carried out as the preliminary fact finding process. Interviewing stakeholders of the system is considered the most effective method of ascertaining the system's requirements. In subsequent phases, the Soft System Approach would be used to study the needs of the system in greater detail. In the preliminary phase, interviews are conducted with two history teachers to gain information about the history project undertaken by all secondary three students, the need, requirements, functions, rules as well as expectations for the digital library. At the same time, a brief questionnaire comprising of 18 questions was distributed to 74 secondary three students. Both the teachers and students were from two selected schools, Klang Convent National Secondary School and the Victoria Institution. The schools are chosen because both provide Internet connections and the schools are situated near numerous cyber cafes, putting the stakeholders in an ICT rich environment. It is assumed that this community would have no problem accessing Internet resources.

The teachers interviewed saw the potential provided by a digital library in providing information to students, while researching for information for their project. The teachers expressed willingly to participate in the development of the proposed system. The teachers also indicated that most of the project report submitted would be thrown away and only the well-done reports are kept for student's reference. The reason for this is the lack of space to keep and maintain all the reports. History, as a subject in the Malaysian secondary school integrated curriculum, is compulsory for all students. The assessment in history comprises two components. The first is the MCQ-type (multiple choice questions) of assessment conducted centrally by the Ministry of Education. The second is the school-based history 
project. Although projects are evaluated at the school level, the marks attained are submitted to the Malaysian Board of Examination. In secondary one, students are given the choice to either research on their family genealogy or their school history. In secondary two and three, the students are required to research on historical buildings, local administrators or historical figures (Sejarah MM1, 2001)

The main purpose of the pilot survey was to find answers to the following questions: How do students conduct research for their history project? This involves knowing the user community, understanding how they interact with systems, their changing needs, and their information seeking behavior. How did students gain access to comprehensive multimedia resources? What are the requirements of good digital repositories? What is required to build useful and enduring digital libraries? The first part contained four questions, which provided the demographic information about the respondents. The second part comprised 14 questions that aimed to ascertain student's level of computer and Internet literacy, the method used to gather information for history projects and the requirements for the proposed system. At this preliminary stage, the researchers' main aim was to ascertain students' general behavior when researching for their historical projects. All respondents in the sample indicated having used computers before and $89 \%$ had access to the Internet. The majority $(56 \%)$ had Internet access from their homes, while others used the Internet from their schools $(20 \%)$, cyber cafes $(14 \%)$, friend's houses $(9 \%)$ and others $(1 \%)$. The students sampled were also frequent users of the Internet with more than $50 \%$ logging on between once to twice a week and $30 \%$ more than twice a week. The type of uses students make of the Internet is indicated in Figure 1. Generally, the three main uses of the Internet are to search for information, e-mail and to chat. A rich picture is indicated in Figure 2 to show the methods of gathering information among secondary three students when completing their history project. The library is still the most frequently used resource, which includes their school libraries, the state and national library. Students also surf the Internet and widely use search engines such as Yahoo and cari.com.my. About $11 \%$ of students indicate going to actual sites such as the museums, national archive and relevant municipal council offices to obtain information. Other methods such as visiting personality's home, distributing questionnaires, interviewing persons, reading magazines, books and using information given by friends are also used.

Figure 1: Types of Internet Use Among the Respondents in the Pilot Study

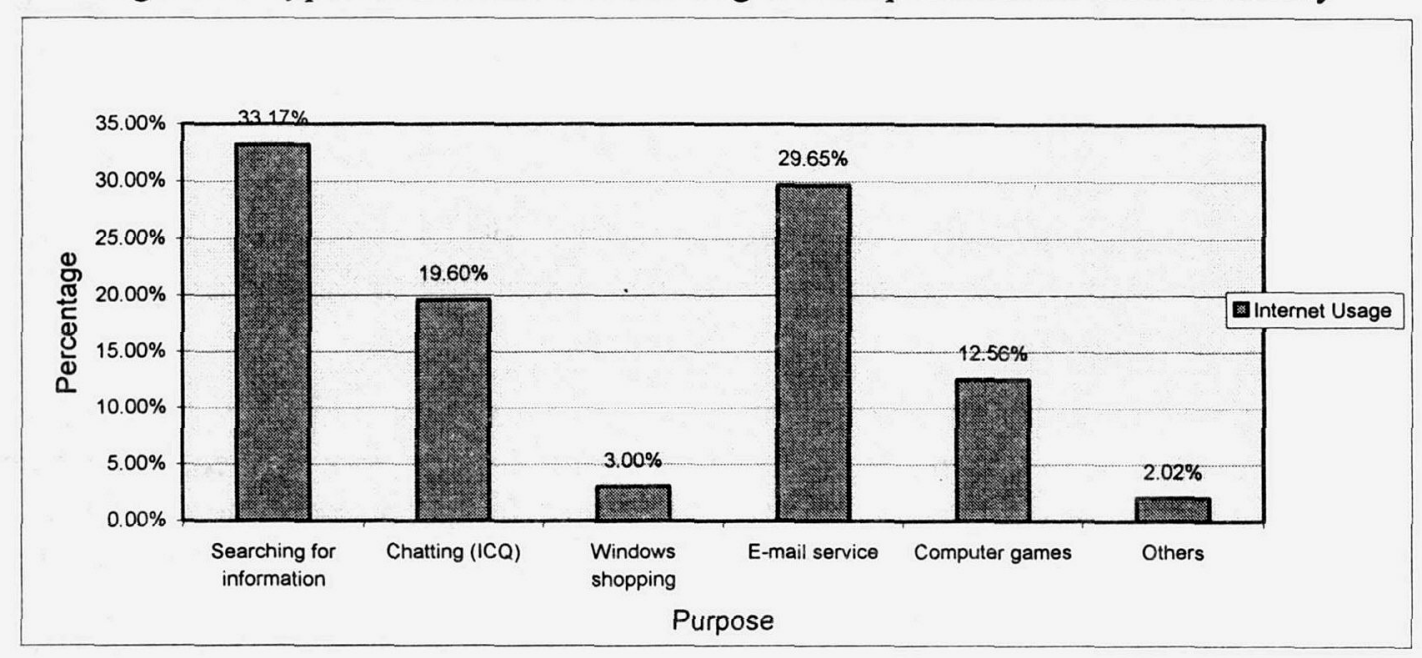

Students in the sample are versatile in their downloading skills of resources from the web. The most popular resources are photographs, charts as well as tables, audio and video files. Students also indicate the types of problems they face when searching for information, 
which includes finding contradictory information from reference sources, insufficient reference sources available; not knowing what reference sources to use or which web sites give the needed information; spending too much time searching on the Internet and not finding enough information; difficulty in getting good quality images or photographs; getting too much irrelevant information and incurring high costs in terms of time and money when visiting the relevant sites for information. Over $90 \%$ of students feel that there is a need for digital libraries of local history information and this would definitely benefit them.

The students also volunteered suggestions as to the functions they would like to see in a digital library. They wanted historical information accompanied by good quality images; current information that is updated continuously; the information provided should be accurate, precise, useful and detailed; and information should be retrievable at a reasonably fast rate as well as searchable through variant keyword searches. Other preferred features are bilingual information; notes on history lessons taught in schools; opportunities to submit question or inquiries; and linkages to other local history web resources. This feedback helps to ascertain the main features required for the proposed historical portal.

Figure 2: Methods Used by Students to Gather Information

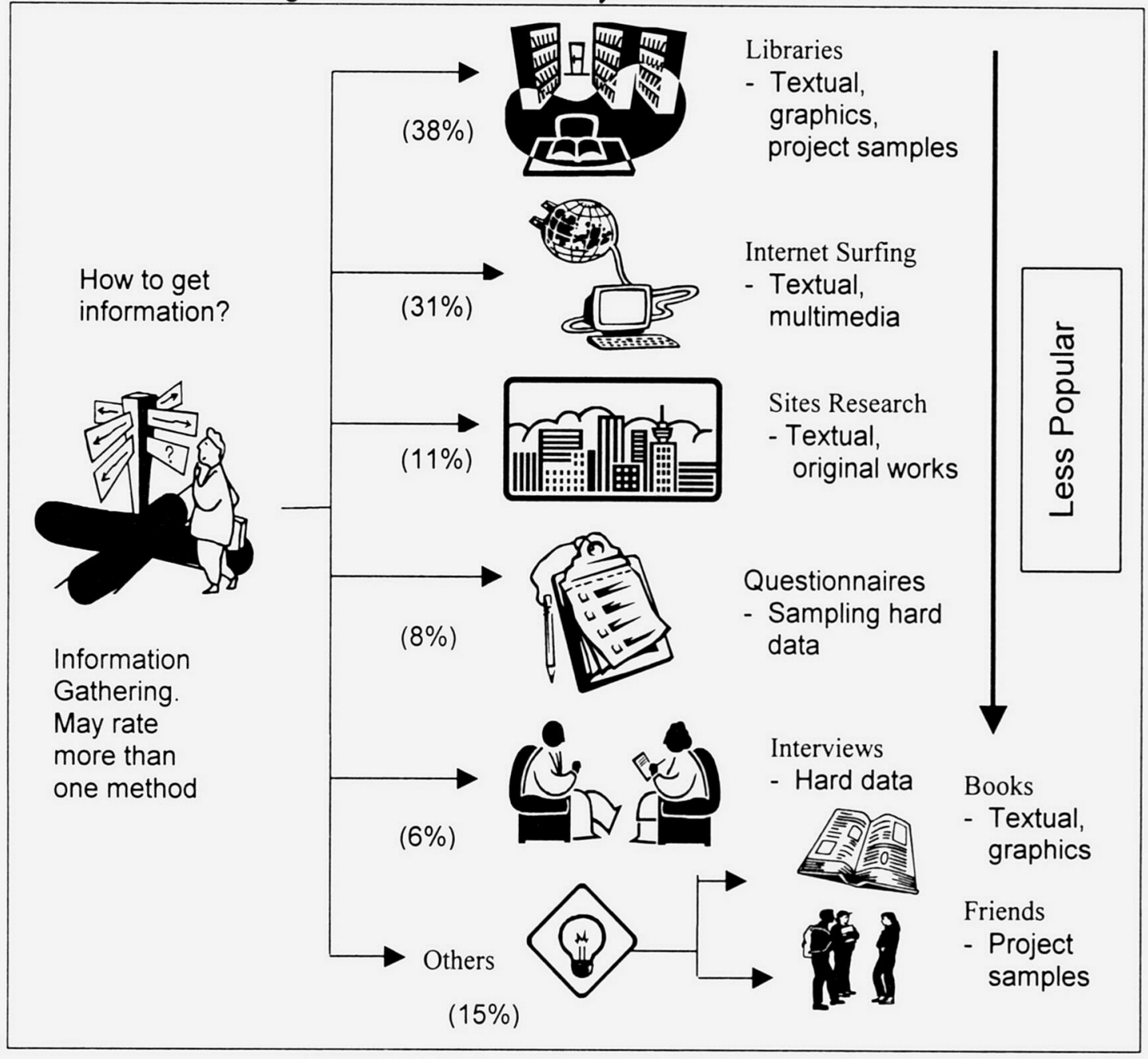

The availability of a web-based historical portal would become an important knowledge portal for data repository and searching for information. It helps students and teachers in a number of ways: (a) it saves valuable time for students who do not have the means to visit sites or locations for information searching or interviewing subjects; (b) it provides access to resources in various formats and allows revisiting or re-accessing 
resources when some information is left out; (c) it promotes the sharing of original and excellent contributions from students (taped interviews with local personalities); (d) it exposes resource managers to the organization of digital resources; (e) it pools talent, vision and resources in the creation of new knowledge; and (f) it promotes awareness of the etiquette of acknowledging or referencing e-resources.

The content of the library is multi-format with the initial test-bed on a biographical portal that can subsequently include portals on historical buildings, sites and collections of historical value (Figure 3). The projected effect on information gathering behavior is indicated in Figure 4.

\section{The System Functions}

The functions proposed by the Malaysian Biographical Portal are given in Figure 5. The security of the system is integrated into the authentication module, which allows only authorized users to access certain administrative functions. The system also provides different access types for different level of users. Database administrators are allowed to access and modify database records, while users can only access and modify their own particulars. Another feature of the system is the enabled knowledge tools that provide value added functions to the portal. Each day the portal would introduce or feature a personality. This feature enables users to see the dynamic side of the portal since the main page of the portal would display a different personality everyday. This feature would also make users more aware of the many personalities that play important roles and does not only provide basic biographical information to users but also allow them to test their basic knowledge on biography related information. The guestbook provides visitors with the opportunity to input comments concerning the portals.

An important function is the indexing, search and retrieval module. These are interdependent features. Authorized systems administrators index digital collections to facilitate retrieval queries. The index function would create a set of keys or an index of terms so that searches can be performed. Textual data would be indexed in detailed metadata. The multimedia contents would be indexed according to their properties, which would include descriptions, categories and keywords. The content managers input these properties when an item is introduced to the database using templates that facilitate the indexing process. The search function that involves users submitting their enquiries using templates and the system searching the indexes or the database for keywords that match this enquiry. The textual data in the biographical portal can be searched through keywords matching and users could also browse the multimedia collections by keywords, location, year, alphabetical order and thumbnail images. All results are assigned relevancy scores based on a basic ranking algorithm (the TF-IDF, term frequency - inversed document frequency algorithm). This ranking algorithm is currently limited to textual searches only. 
Figure 3: The Proposed Historical Portal (COREDEV)

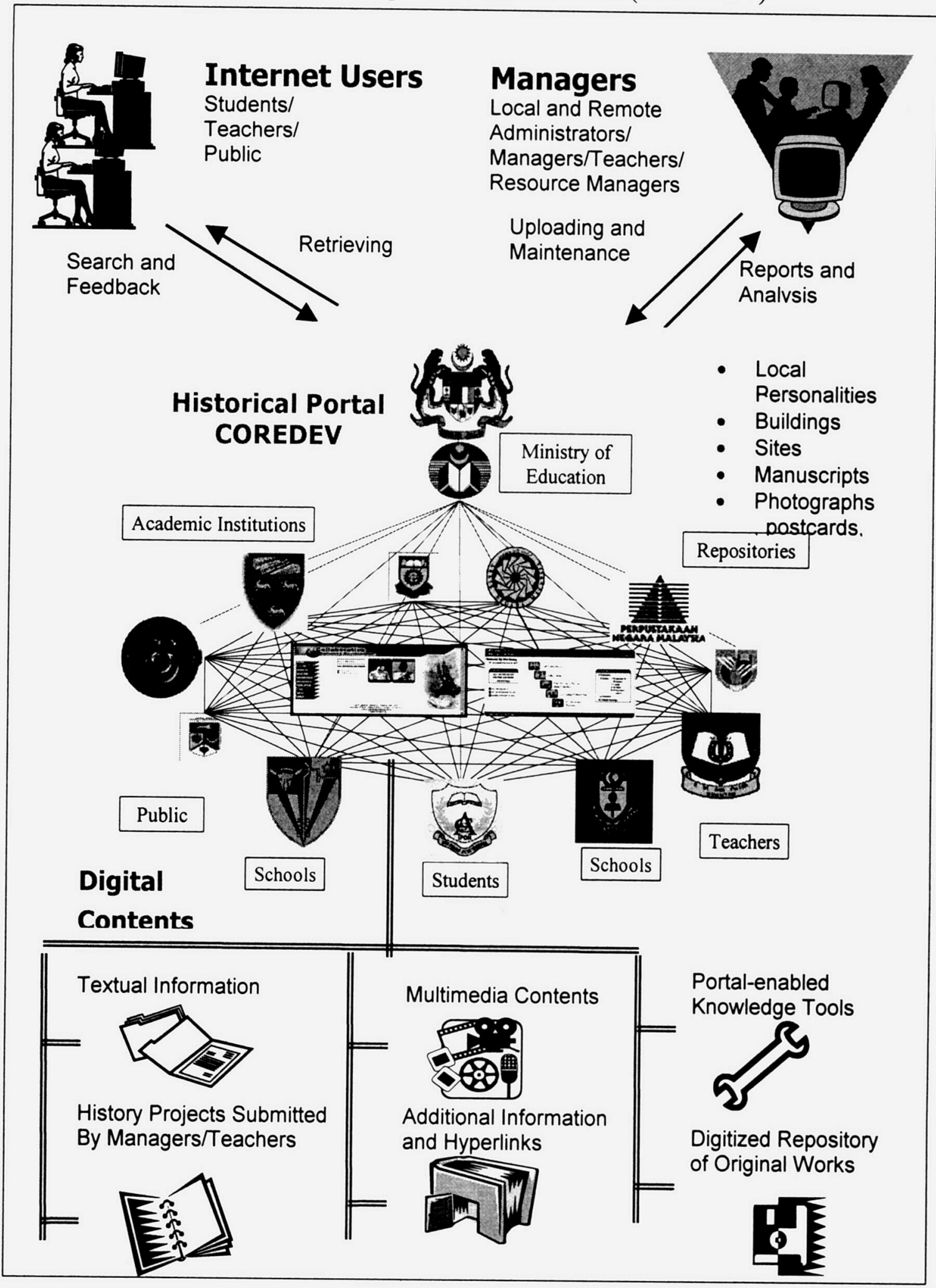


Figure 4: The Projected Information Gathering Behavior Using the Historical Portal

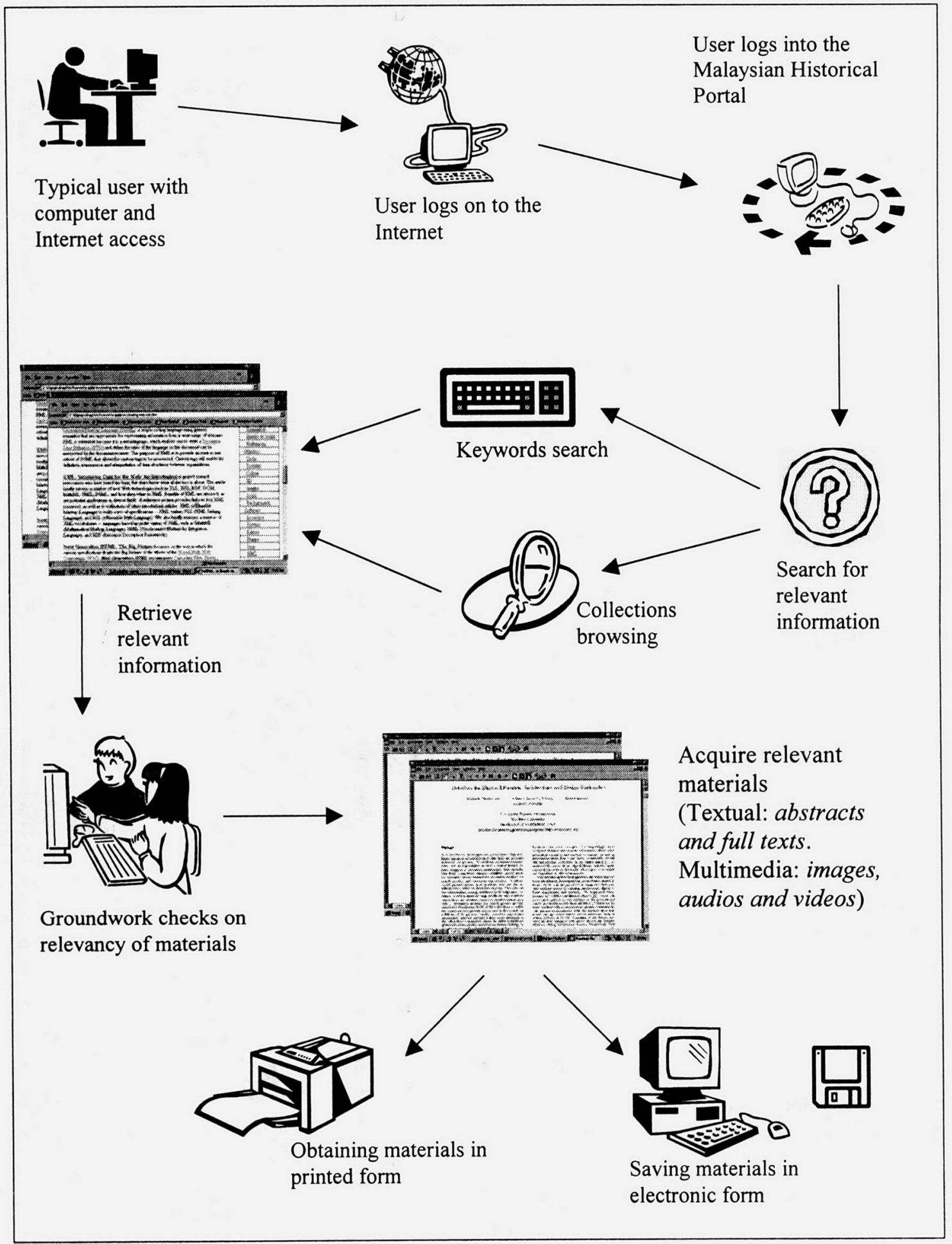

The main administrator's module provides data manipulation functions. This feature enables authorized users to submit or upload their collections and student's projects into the portal's database. It provides a mechanism to share and store resources, making these accessible to Internet users and encourages knowledge sharing. The data manipulation function allows users to view, modify and delete entries in the portal's database. The portal also provides guides and basic information to assist users to use the system effectively. This 
comprises basic features such as search tips, help information, and giving users step-by-step procedures to perform certain tasks. Other information provided is a brief introduction about the system, frequently asked questions (FAQ), terms and conditions for those interested in participating and links to other related resources. The system is able to track those logging in into the dataset. These records would be used to produce statistical tables or reports for a certain period of time, whenever required.

The biographical portal is developed based on the three-tier client/server approach. The first tier is the client, which constitutes computers with Internet Explorer (4.0 or above) that provides user interface, and process users input and display outputs. The middle-tier runs on a server (referred to as the application server), comprising Internet Information Server 5.0 as the web server. All application or files will reside here. The web server processes the request from the client and returns the result required in web pages format. It will process any data request by linking to the database server. The third tier runs on a second server comprising the Microsoft SQL Server 7.0 as the database server that maintains the data records required by the middle tier. Every inquiry requested from the web server will be authenticated first before the results are returned to the web server. This architecture provides modularity as it is easier to modify one tier without affecting the other tiers, it increases performance when large number of users logs in and improves openness, reusability and scalability; and hides the complexity of distributed processing from users.

During this preliminary stage, the prototype was pilot tested in a school (Sekolah Menengah Taman SEA) in Petaling Jaya, Selangor. Two teachers viewed the system and gave their ratings to a list of 10 features rated on a 5-point scale of 1 (weak) to 5 (excellent) related to the design features. The design criteria includes features such as navigation, hyperlinks; colors, background images; download time; image or graphic arrangements; animation; text style; text color; overall color combinations; ease of reading contents; and overall display of the digital library. The teachers gave their opinion about the functionality of the system, its search functions, its help and information features, its contents, its usefulness as a resource for student's project and its effectiveness in motivating students to learn history. The teachers found no difficulties in answering the questions posed and this rating scale would be used for the systems testing on a larger scale in the second phase of this project. On the design features, both teachers and students rated seven out of the 10 features as good and generally understood the functions and purpose of the system and agreed that the system would benefit them. One drawback from the evaluation exercise is the lack of skills shown by the teachers in handling the computer and it is foreseen that human factors could be the main problem in the successful implementation of the collaborative digital library. Generally, the students show better adeptness in handling the system and rate the design features as either excellent or good. The students also generally agree that such a system would be a useful resource for the completion of their history project. 


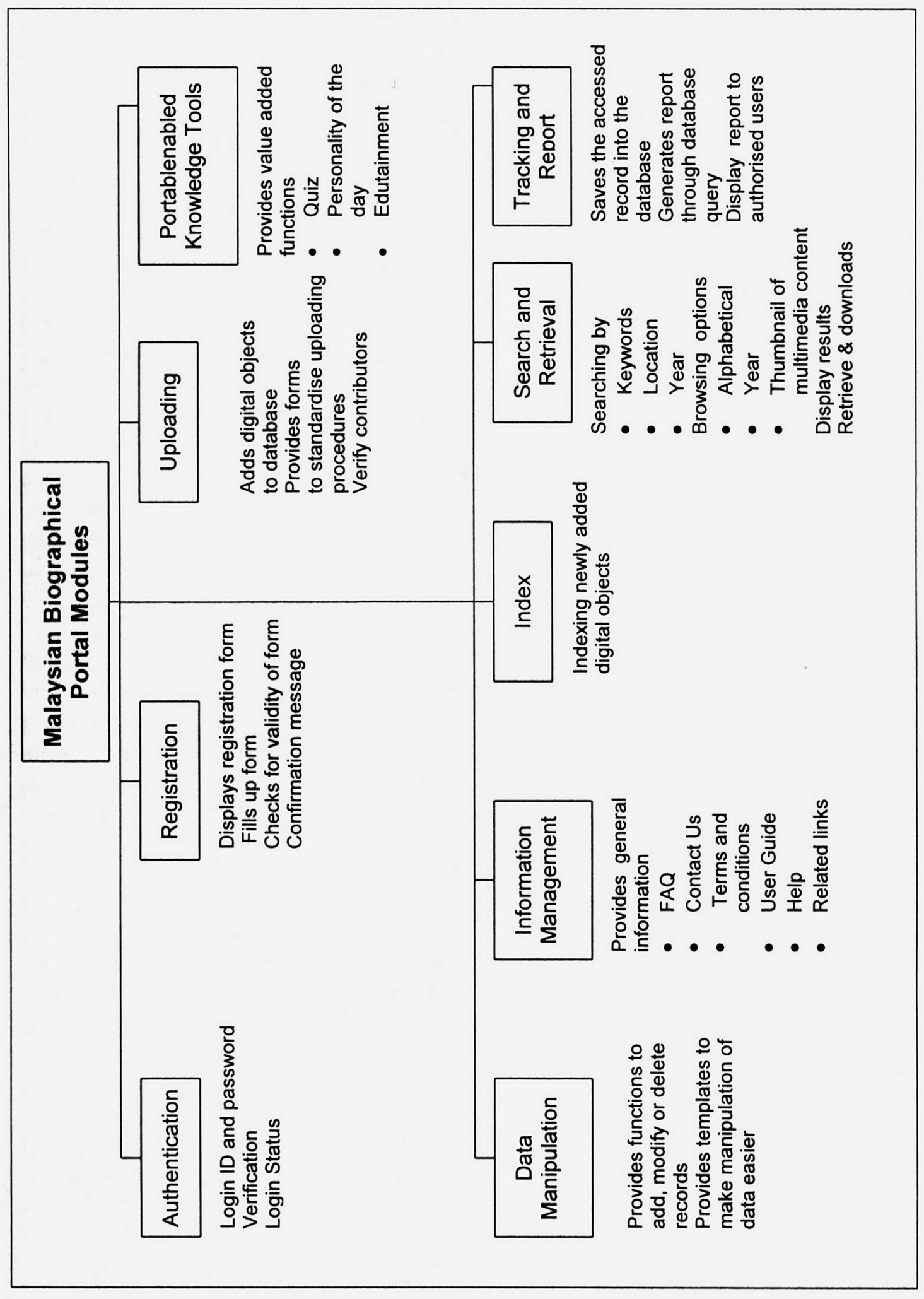

\section{Conclusion}

The process of developing COREDEV is both challenging and demanding. The biographical portal is the domain used as the test-bed towards the implementation of a fully integrated collaborative digital library of historical resources, which serves the needs of the Malaysian educational community. The portal emphasizes collaborative resource 
development as well as knowledge sharing and such a system requires a robust and efficient retrieval system. There are very few local resources or similar systems in Malaysia that can be used as reference. As such, the functional development was mainly based on the literature read about such ventures abroad associated with the development of digital libraries and an understanding of the domain's environment within the Malaysian context. The interviews and the pilot surveys provide invaluable information about information gathering behavior and the community's perception of digital libraries.

The prototype portal incorporates the five main basic features proposed by IBM DB2 Digital Library (1998). The uploading, indexing, search and retrieval modules provides for creation, capturing and sharing data from distributed sites, supporting collaborative resource development between various user groups. This is the strength of the system as it encourages active participation, which would in the long run produce the desired outcome in terms of ICT literate teachers and students and the experience of creation or publishing in digital libraries. The ICT in this context is only the enabler to the creation of a content rich digital library. The system supports multi-format digital resources (text, images, audio and video clips) and therefore exposes the learning community to the unique features of digital libraries. The biographical portal also provides facilities for searching the contents of the digital libraries by processing simple keyword searches or specifying specific occurrences of words in specific fields to a combination of terms using Boolean operators. An extended feature is the provision of bilingual search and retrieval screens (Malay or English language). Users could also determine the number of records to be displayed in search result pages $(5,10$ or 20 records). An added feature is the relevancy of information provided to users. Besides obtaining results based on submitted search queries, users could also browse the total contents of the library or by specific category of objects. Thumbnail images are displayed for browsing before users can zoom for specific detail of any objects. The Indexing module has incorporated a basic vocabulary of synonymous terms, to help resources managers assign indexing terms to specific resources. This list is not currently exhaustive and requires updating from time to time. In terms of access rights management, the portal allows uploads from any member but each upload requires validation from assigned resource managers before it is searchable through the Internet. Although, this feature ensures some quality control, the pressure put on resource managers to process uploads remains to be monitored. Besides these basic features, the biographical portal provides additional facilities such as general information, help and edutainment modules as well as the reporting module.

The biographical portal has tried to incorporate features expressed by the "keystone principles" proposed by the US College and Research Libraries Group (An action plan.., 2001) as an action plan for value-based digital library. The keystone principles expressed urgency in three areas that ensure and require user-centered actions. The principles were formulated for academic and research libraries, which has universal applications to all libraries. Within the context of adding value to digital libraries the following principles form the basis of its development.

(a) It accepts the principle that access to information is a public good. As such information must be available free of bias and easily accessible so that the right to read and to know is not threatened. To realize this principle resources providers should collaborate to create local, state, national level resource and provide the means to create these resources. COREDEV caters for a collaborative environment that promotes the creation and sharing of resources.

(b) It accepts the principle of access to bias free systems. This would enable partners to create, disseminate new formats of knowledge to support learning and share the cost of 
creating information. To actualize this, partners should allocate a budget for the creation of digital information and new access systems. This would enable the libraries to assume its information management role.

(c) Affirm the idea that the library is a nexus for learning and the sharing of knowledge. The stress is on improving the quality of learning situations, making use of IT as the enabler. In this context, the library is seen as the hub of the knowledge network. In order to actualize this, partnerships need to be formed and electronic spaces must be made available to create virtual environments that support research and learning activities.

The proposed digital library of historical resources is a system that provides for the interaction of data producers and users within a complex distributed system. It should provide for building collections collectively by member partners in three ways: creation of original digital works, digitization of paper-based resources and providing linkages to other relevant web sites. The biographical portal is the domain used as the test-bed in the first phase of the digital library project. To successfully implement the collaboration between partners, a number of problems need to be ironed out. The teachers involved need to be given training in publishing digital resources and the skill of indexing and validating the resources to ensure that the contents of the library can be efficiently retrieved. Both teachers and students must accept the reality that the richness in content of the digital library is dependent upon their active participation as partners. The outcome of this involvement is imparting ICT awareness and skills to the educational community. Another important skill needed is the ability to reference or cite resources used correctly. Subsequent phases of this digital library project will further investigate the requirements of users by applying the survey instruments to wider sample groups; expanding contents to include resources on historical buildings and sites; incorporating digital library history lessons, teaching tools, and examination questions bank on history for lower secondary schools.

\section{References}

An action plan for value-based librarianship: the Keystone Principles. (2001). College \& Research Libraries News. Available at: http:/www.ala.org/acrl/keystone.html.

American Memory Historical Collection for the National Digital Library. Located at:http://memory.loc.gov/

Borgman, C.L. et al. (1996). UCLA-NSF social aspects of digital libraries workshop: final report. Available at: http://dlis.gseis. ucla.edu/DL/UCLA_DL_Report. html.

Bunker, G. and Zick, G. (1999). Collaboration as a key to digital library development: high performance image management at the University of Washington. D-lib Magazine, $5(3): 1-14$

Carpenter, Beth. (2000). A field guide for collaborative collection development. Computers in Libraries, 20(6):28-33.

Coleman, Ross. (1997). Australian cooperative digitization project, 1840-1845. Available at: http://www.ariadne.ac.uk/issue8/digitisation/intro.html. 
Hedman, Anders. (1999). Creating digital libraries together - collaboration, multimodality and plurality. Fourth SIGCSE/SIDCUE on Innovation and Technology in Computer Science Education, Cracow, Poland: 147-150.

IBM DB2 Digital Library Architecture. (1998). Located at: http://www 4.ibm.com/software/is/dig-lib/v2factsheet/page3.htm

Marchionini, G., et al. (1996). Content + connectivity=>community: digital resources for a learning community. Proceedings of the second ACM International Conference on Digital Libraries, Philadelphia: 212-220.

MyLibrary. Located at: http://www.mylib.com.my

The New York Public Library Digital Library Collection. Located at: http://digital.nypl.org/

The New Zealand Digital Library. Located at: http://www.nzdl.org/cgi-bin/library.

Noerr, P. (2000). The digital library tool kit. $2^{\text {nd }}$ ed. Sun Microsystems. Available at: http://www.sun.com/products-n-solutions/edu/libraries/digitaltoolkit.html.

Sejarah MM1. (2001). Available at: http://www.klik.com.my/sj/know/mm0103.htm.

Stahl, Gerry. A model of collaborative knowledge building. Proceedings of the ComputerSupported Collaborative Learning (CSCL) 2000. Also available at: http://orgwis.gmd. de/ gerry/publications/conferences/2000/icls/index.html

Tull, Laura. (2002). Cooperative digital imaging projects: the Greater Cincinati Memory Project, The Electronic Library 20(1,) 2002: 1-5.

Wilensky, Robert (2000). Digital library resources as a basis for collaborative work. JASIS, 51(3): 129

Wolf, Milton T and Bloss, Marjorie E. (1998). Without walls means collaboration. Information Technology and Libraries, 17(4):212-215. 
APPENDIX: Selected Print Screens from the COREDEV

A short presentation in Flash that introduces the system

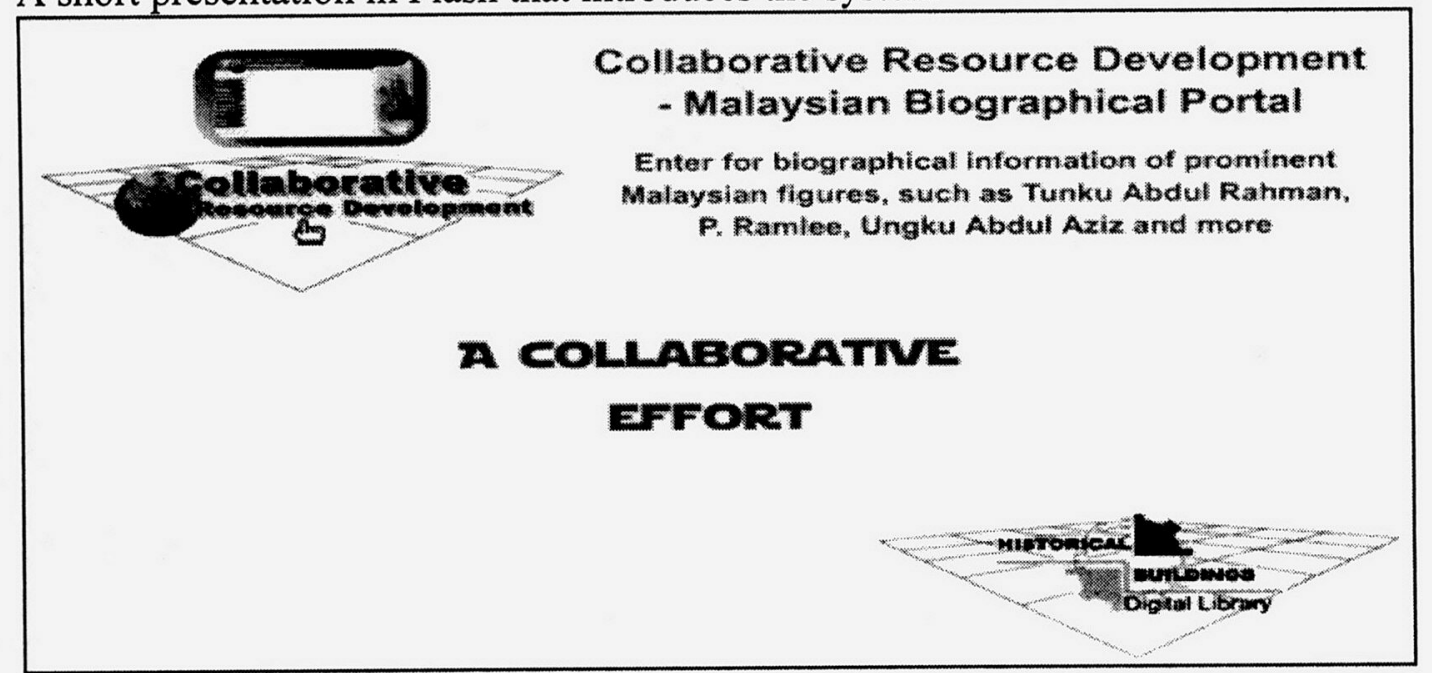

The main page of the Malaysian Biographical Portal

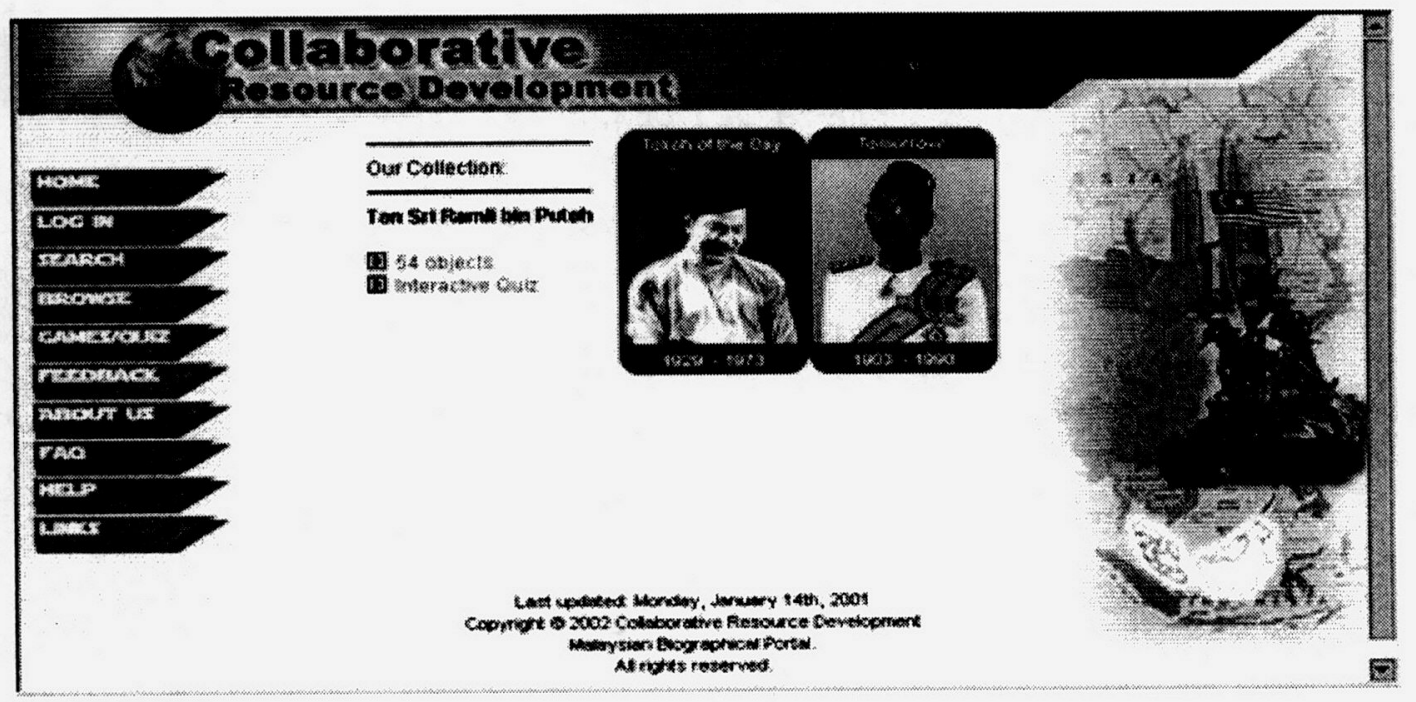


The Login Page

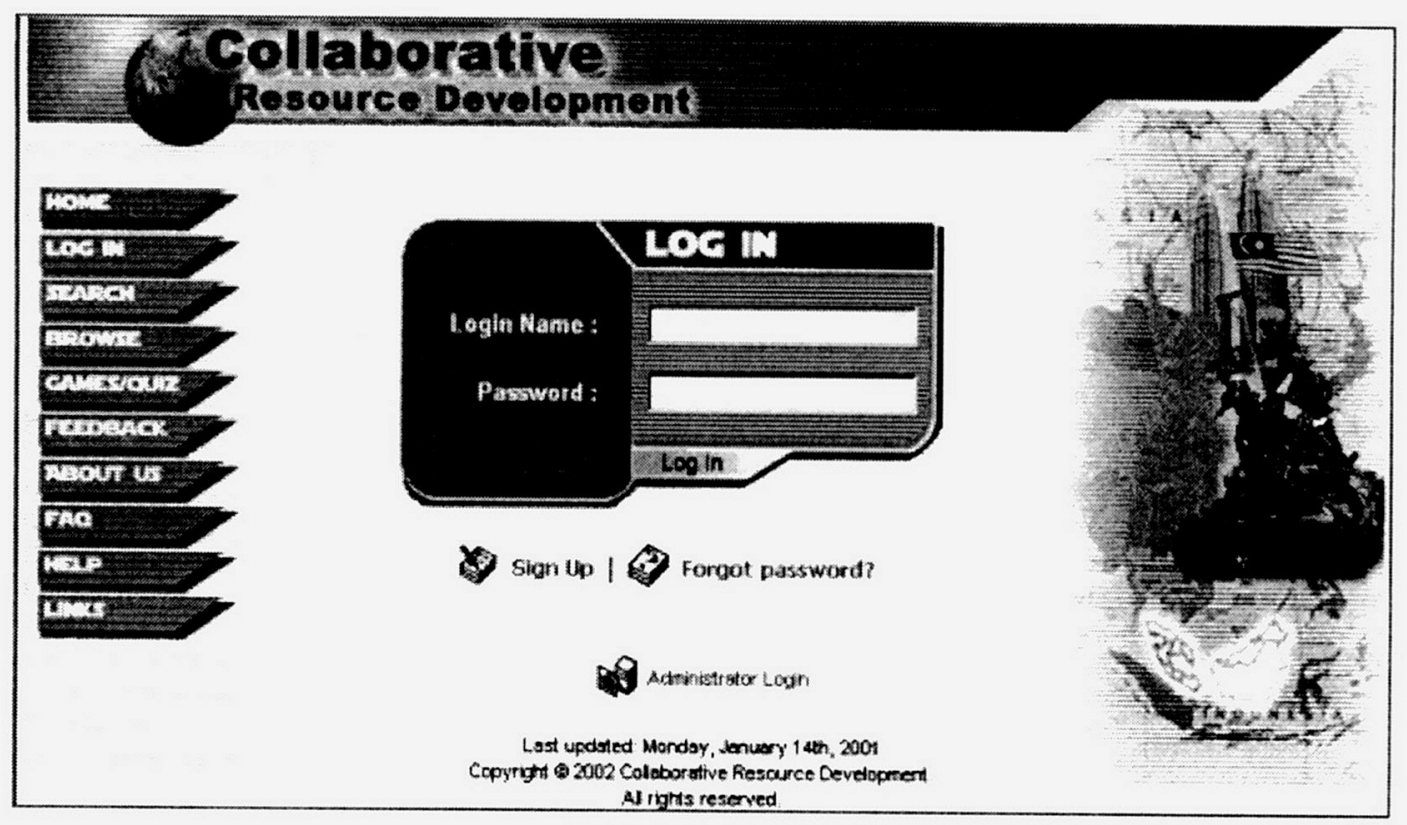


The Registration Form

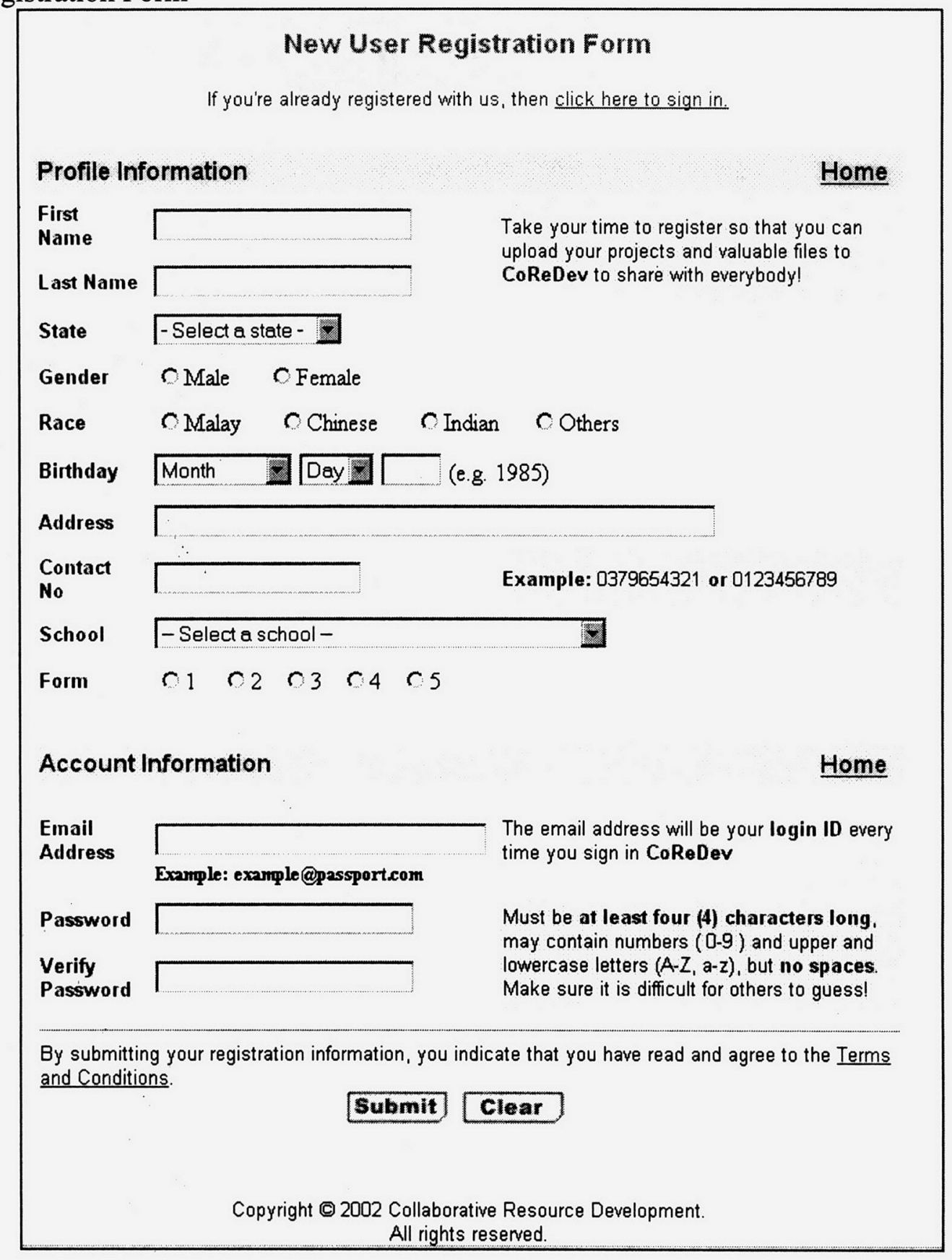


The User's Page

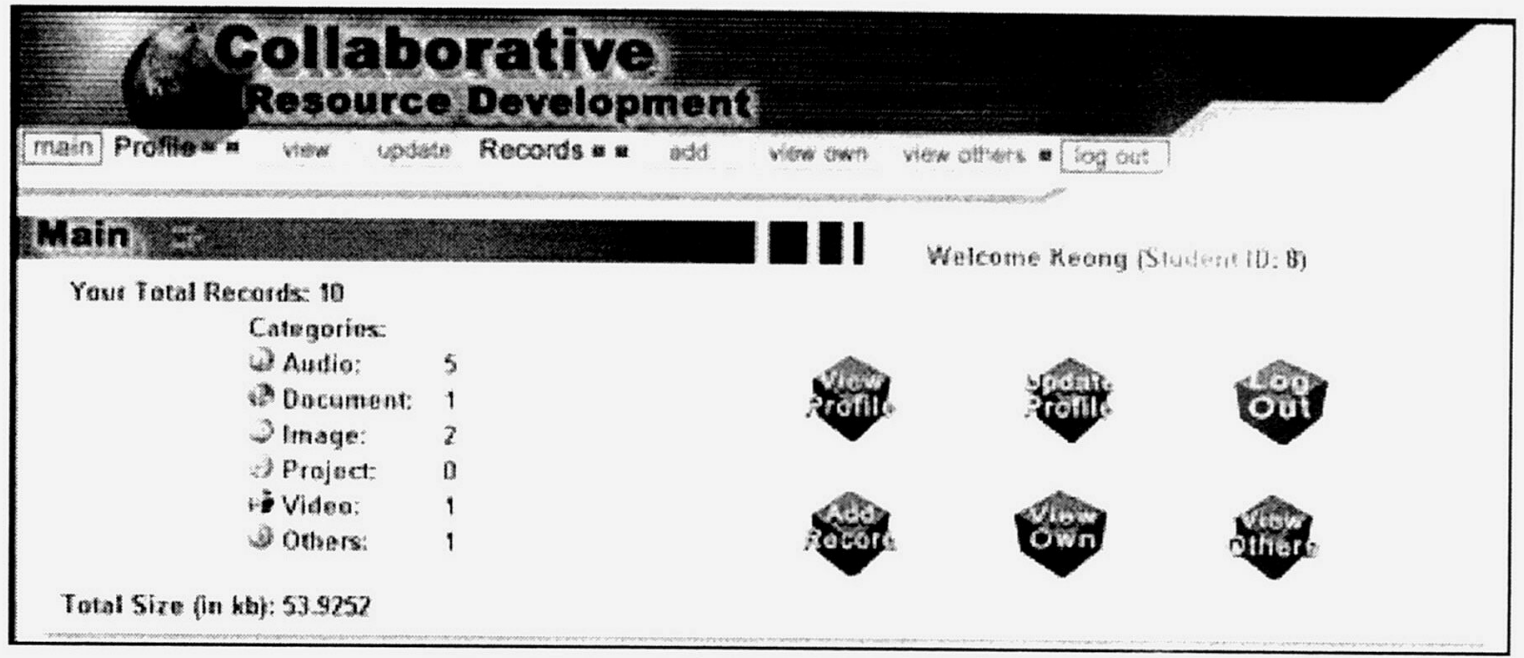

The Administration Menu page

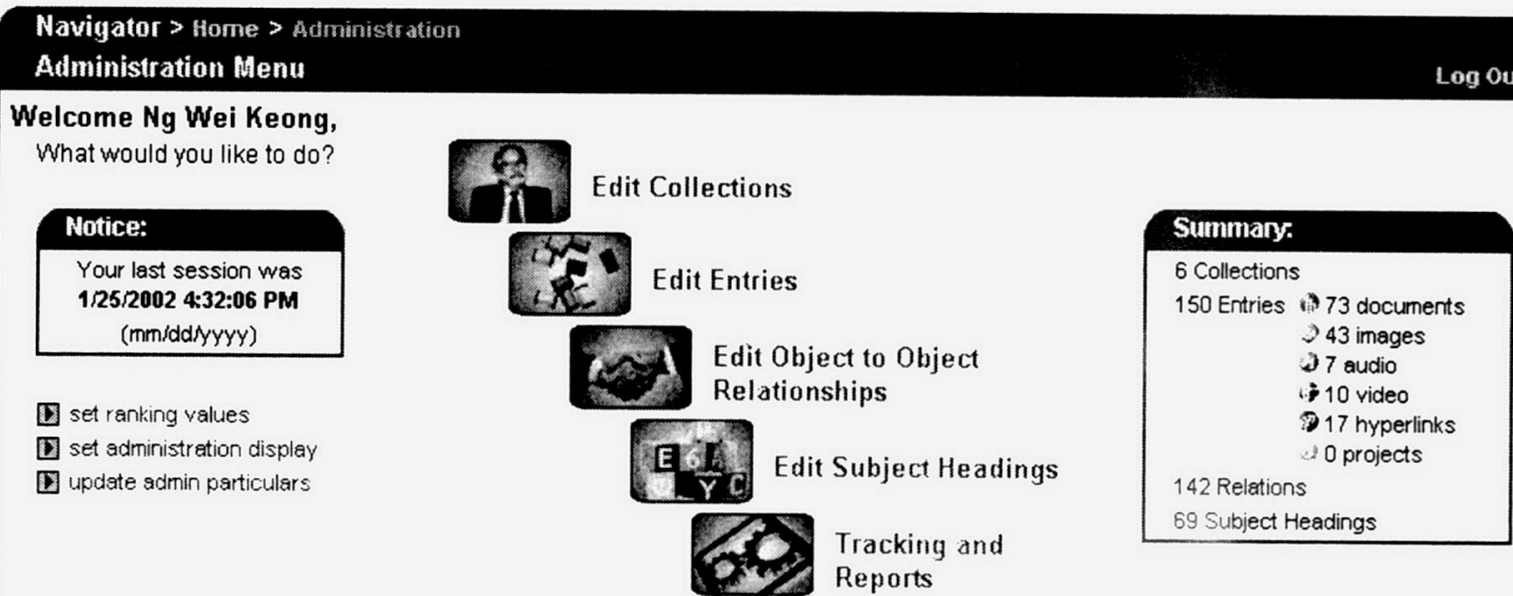

\section{Administration Henu}

Browsing interface

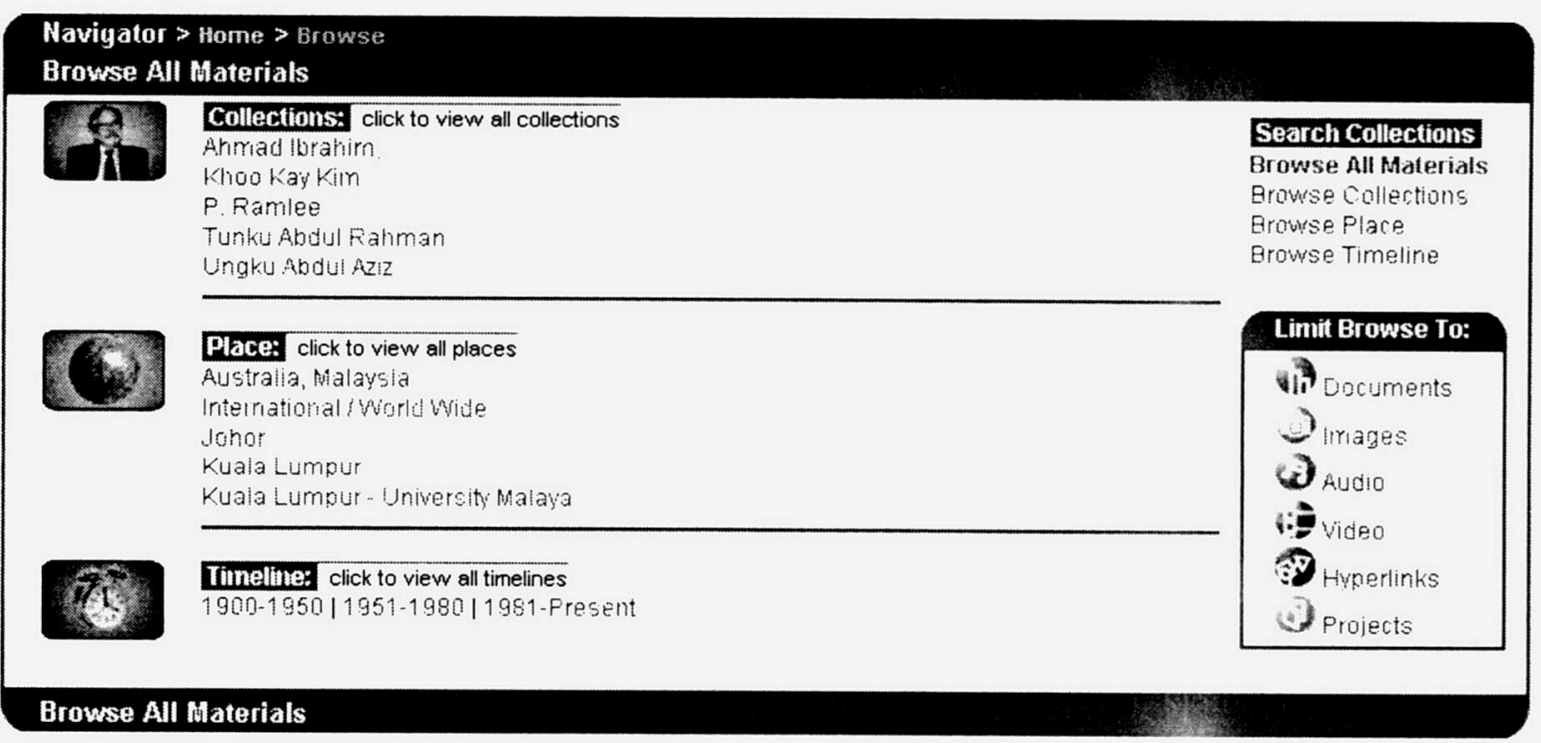



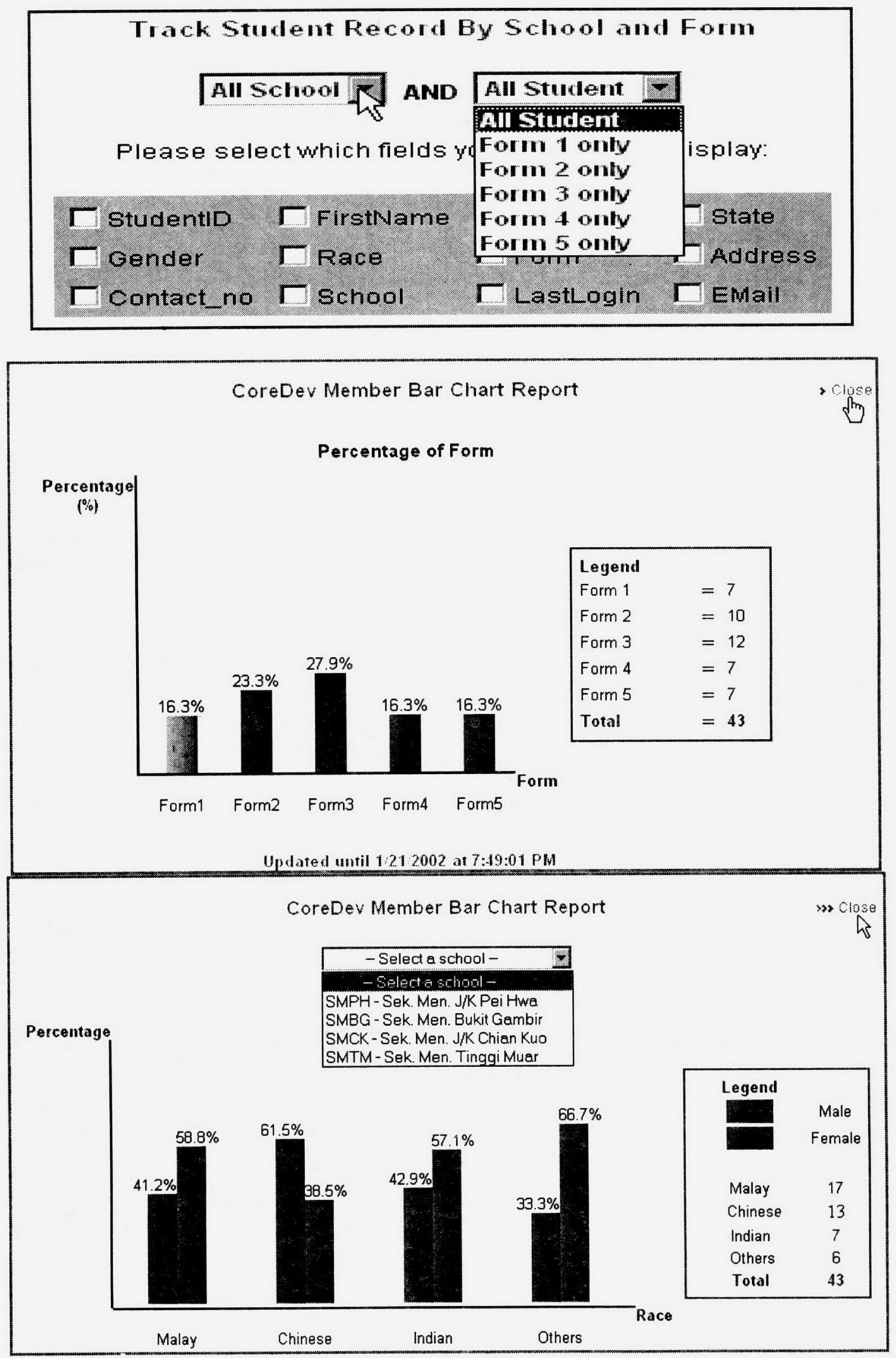